\title{
An Exploratory Study of a Research Culture Development by Administrators, Lecturers and Clinical Specialists in Nursing
}

\author{
Dr Jennifer C F Loke ${ }^{1, *}$, Dr Kah Wai Lee ${ }^{2}$, Dr Mary Laurenson ${ }^{3}$ Ms Asmah Mohd Noor ${ }^{4}$ \\ ${ }^{1}$ Faculty of Health and Social Care/Nursing and Midwifery, University of Hull, Hull, United Kingdom \\ ${ }^{2}$ Park View Surgery/General Practice; Hull York Medical School/Medicine, University of Hull/York University, United Kingdom \\ ${ }^{3}$ Faculty of Health and Social Care/Health Professional Studies, University of Hull, Hull, United Kingdom \\ ${ }^{4}$ School of Health Sciences/Nursing, Nanyang Polytechnic, Singapore \\ *Corresponding author (Email: j.loke@ @ull.ac.uk)
}

\begin{abstract}
Context: Escalating healthcare demands combined with diminishing resources underline the importance of ensuring nurses in leading roles, having the capacity to conduct evidence-based research to inform practice.

Aims: This study explored the perceptions of research knowledge and experiences of nurses in administrative, teaching and clinical specialist positions to highlight gaps in research provision within educational institutions and healthcare organisations in Singapore.

Design/Methods: A mixed-method exploratory descriptive design, using a questionnaire with open and closed questions was employed to obtain the views of nurses on their capacity in conducting research. Convenience sampling was employed in 3 research seminars in Singapore between July-August 2011.

Results: Forty seven nurses were recruited and they confirmed good research knowledge and skills but indicated the need for enhanced educational preparation and organisational support to fully embrace a research culture.

Conclusions: Research in nursing requires prioritisation and support in educational training and healthcare settings. Otherwise, conducting research would continue to be a lesser priority for nurses, even if they were in teaching or clinical positions which provided significant opportunities to lead or facilitate research. Given that role modeling enhances research culture in nursing, within education and clinical settings, nurses in leadership positions require confidence in conducting research. However, without prioritising research, and filtering this down through the nursing hierarchical system to promote a research culture, new knowledge to improve practice will remain elusive.
\end{abstract}

Keywords - Conducting research, evidence-based healthcare practice, nurse education, nurse administrators, clinicians and lecturers, healthcare organisational culture and support.

\section{Introduction}

Since the assertion on nurse leaders' extra responsibilities to oversee nurses' activities in research data collection and analysis and dissemination of findings (Pettengill et al. 1994), there was intense effort on fostering their abilities in creating foundation of clinical inquiry (Terry et al. 2011). Certainly, the emphasis on evidence-based practice in healthcare has increased the challenges for nurse leaders in terms of their accountability for nurses' activities (Flesner et al. 2005). Nevertheless many strategic measures to embrace a research culture in nursing were at political and institutional levels. Hence, the responsibility to promote a research culture was not solely attributed to nurse leaders. For example, hospital-based nurse education was moved into higher education institutions where research was introduced in the curriculum to increase awareness and capacity building of nurses to promote research output in clinical settings (Meyer et al. 2003, Woodward et al. 2007). Inevitably, nurse lecturers in higher education also shared major responsibility in building the clinical research culture in practice (Profetto-McGrath et al. 2009). Alongside nurse lecturers, nurse clinicians who delivered specialised nursing care based on advanced skills were also expected to have the capacity to lead research activities (Reiter 1996). This expectation was a result of the fact that these nurses provided direct specialised patient care (Fitzgerald et al. 2003, Nelson et al. 2007). In other words, there was an expectation for nurse lecturers and nurse clinicians to undertake leading roles in research alongside nurse administrators.

\section{Background}

Singapore was proactive in joining the international evidence-based movement and promoting a nursing research culture alongside medical research development. Initial steps included developing nurse education to diploma 
levels in the mid 1990s, and later progressed to provision at degree level in the mid 2000s. Overall, nurse education provision was underpinned by a curriculum in which research was vital to establish best practice. In fact, the concept of evidence-based practice was introduced in the country whilst it was still gaining ground in the West. Since a higher level of confidence in research preparation was found amongst nurse lecturers who held a degree (Clifford 1997) and nurse educators' research utilisation behaviours which facilitated evidence-based practice were also, statistically-significant correlated with their total critical thinking dispositions (Milner 2005, Profetto-McGrath 2009), there was enthusiastic development of research and critical thinking skills of nurse educators. In the early 1990s, qualified nurses who had good clinical skills, and students with outstanding academic performances at Advanced General Certificate levels, were given the opportunity to pursue a degree in nursing overseas, mainly in the United Kingdom (UK) and Australia based on either the scholarship offered by the World Health Organisation or the Singapore Public Service Commission. These scholarships were offered with an aim that the nurse scholars would return to assume leadership roles such as nurse administrators, nurse lecturers and nurse clinicians to add value to evidence-based practice. At individual level, nurses who were financially able would pursue top-up degrees from overseas universities. These governmental and individual efforts had indeed resulted in many more nurses functioning as administrators, lecturers and clinicians in the mid 1990s. These individuals as registered nurses, albeit having very different job scopes and role functions, all have similar responsibilities in motivating and inspiring nursing research practices which were characteristic features of effective leadership behaviours (Chiok-Foong Loke 2001, Kouzes \& Posner 2012).

Indeed by the new millennium, many seminars on research and evidence-based practice were conducted to promote a research culture in nursing (Loke 2001). Following advances in the West, the advanced nurse practitioner roles were also introduced in 2003 by a nurse administrator to increase opportunities for research participation by local nurses (Premararni 2006). Despite these observations, the success of research culture by these specially prepared nurses within Singapore remained unexplored. Certainly, whether nurse lecturers had translated theory to practice to develop a research culture and subsequently sustained in practice by nurse administrators and clinicians were not established.

Being able to motivate and inspire were once identified as important leadership behaviours in times of financial instability in Singapore (Chiok-Foong Loke, 2001). Given the intense demands for evidence-based nursing in the current atmosphere of global financial instability, this study explored the perceptions of research knowledge and skills of nurse administrators, lecturers and clinicians, with an aim to uncover their experiences in nursing research activities, and their critical leading role in guiding evidence-based practice. In essence, other than nurse administrators, this study seeks to build the knowledge base around the effectiveness of promoting a research culture by nurse lecturers and clinicians who were in similar critical positions in influencing research.

\section{Literature Review}

Research studies on nursing research activities tended to focus on nurses in general rather than nurse administrators, lecturers and clinicians. Also, studies were limited and these studies reported limited evidence of nurses undertaking research (Clifford \& Murray 2001, Kuuppelomaki \& Tuomi 2003, Oh 2008, Woodward et al 2007). These explained the general lack of research to guide practice (Thompson et al 2001) and insufficient research dissemination (Clifford 2004). The few papers available for review also suggested that nurses lacked research knowledge and skills, and tended to view undertaking research as a separate activity to professional practice which involved emotional and personal investment (Clifford \& Murray 2001, Kuuppelomaki \& Tuomi 2003). As a result, some nurses demonstrated a lack of interest in practical application of research knowledge and skills. Indeed, many conducted research only if it was part of an academic pursuit (Kuuppelomaki \& Tuomi 2003, Loke et al. 2012).

Gender issues were also identified as a reason for the lack of research activities amongst nurses, who by the majority were female (Hicks 1996). In other cases, political dynamics were found to have adversely affected practitioners' levels of research activities (Coghlan \& Casey 2001, Meyer et al. 2003). For example, nurses who were actively involved in research were perceived as 'outsiders' of the organisation (Meyer et al. 2003). Another barrier to nurses' active research participation was the perception that qualitative paradigms were not appreciated, yet these relate more to nursing care approaches (Redwood 2005). Other than the lack of organisational support, inadequate time allocation to undertake research was also reported as the main problem (Oh 2008, Tan et al. 2012, Tsai 2000).

Despite these challenges, some nurses were found to be motivated to conduct research to address clinical problems for quality patient care (Hicks 1996, Tanner \& Hale 2002). Unfortunately, nurses generally felt unsupported in conducting research not only by medical doctors, but also by managers (Tanner \& Hale 2002, Roxburg 2006). Yet, motivation and support were, in nurses' opinions, crucial influencing factors for undertaking research activities (Clifford \& Murray 2001; Tanner \& Hale 2002, Roxburg 2006).

Due to the low uptake by nurses in conducting research, the assertion was that there was a need for theory and practice integration to progress nursing research (Jolley 2002). In this regard, nurse leaders in education and practice were critical role models for demonstrating the integration of research theory into nursing practice. However, whilst this was advocated, Cooke et al. (2002) outlined infrastructure difficulties, and Adamsen et al. (2003) outlined variances in the nursing curriculum for research training. Both these aspects are critical barriers to undertaking research. Based on a leadership and management viewpoint, difficulties in integrating research into nursing could only be resolved if there was a paradigm shift in organisational culture to promote research (Gill 2004, 
McNicholl, 2008). In fact, Rycroft-Malone (2008) had warned that any increase in analytical research skills would not lead to usage unless there was a culture change. Furthermore, Joyce (2009) suggested education has some accountability in ensuring that research theory and practice were aligned. Jones (2010) who supported this view, concluded that time allocation was necessary to enable research to flourish.

In essence, findings to date demonstrate a consensus about the importance of leadership and management roles and responsibilities in promoting and facilitating a research culture in practice (Adamsen et al. 2003, McNicholl et al. 2008, Rycroft-Malone 2008). In this regard, it became critical to know the extent to which nurses in administrative, education specialised clinical positions were role models in research activities. In this instance, it is applied to Singapore, towards providing an inclusive nursing evidence-based practice movement.

\section{Design and Methods}

This study employed a mixed-method exploratory descriptive design which was predominantly qualitative in nature. It was based on a convenience sample obtained in 3 research seminars focusing on research methods conducted by the first author on separate occasions between July and August 2011 in Singapore. The study used a questionnaire based on open and closed questions to measure participants' demographic data, their perception of research knowledge, skills and experiences, and also, the values of research activities and organisational support offered. The questionnaire was developed based on the literature review and revised after being piloted amongst 10 nurse lecturers and 5 clinical nurse administrators (Table 1). They were distributed, completed and returned before the start of the seminars. Respondents had the opportunity to decline participation in the questionnaire which provided the aim and purpose of the study and guidelines on the way to access research support in the local context. The study was approved by the faculty ethics committee of the first and third author.

A descriptive statistical analysis based on the Statistical Package for Social Sciences (SPSS) version 19 was performed on the responses to the closed questions to provide insight of respondents' demographic data, research profile and views on research activities in relation to organisational support.

Data analysis of the open ended questions was undertaken through a qualitative interpretative descriptive approach by coding the responses according to the work of Ryan and Bernard (2003:2) which included:

“(1) an analysis of words (word repetitions, key-indigenous terms, and key-words-in contexts); (2) a careful reading of larger blocks of texts (compare and contrast, social science queries, and searching for missing information); (3) an intentional analysis of linguistic features (metaphors, transitions, connectors); and (4) the physical manipulation of texts (unmarked texts, pawing, and cut and sort procedures)".

Through this process the researchers were able to extract the most important themes from the respondents' perspectives. This enabled the researchers the opportunity to analytically interpret the significance and meaning of the respondents' explanations of the conditions and interaction involved in their educational and clinical practice environments. It therefore provided a distinctive emphasis in relation to nursing and to individuals' real life experiences (Balls 2009).

Table 1.Changes to Questions to address Content Validity

\begin{tabular}{|l|l|}
\hline Initial statements in questionnaire & Revised questions \\
\hline $\begin{array}{l}\text { Research preparation } \\
\text { Absence of question }\end{array}$ & $\begin{array}{l}\text { Obtaining research paper from: } \\
\text { Employer libraries/search engines } \\
\text { subscribed by employers }\end{array}$ \\
\hline $\begin{array}{l}\text { I am prepared to self fund to gain access of } \\
\text { research papers }\end{array}$ & $\begin{array}{l}\text { "I am willing to pay to gain access to } \\
\text { research papers" }\end{array}$ \\
\hline $\begin{array}{l}\text { Research experiences and skills } \\
\text { "I need to acquire more skills for } \\
\text { conducting research" }\end{array}$ & $\begin{array}{l}\text { "I need to acquire more skills for } \\
\text { conducting research" }\end{array}$ \\
\hline $\begin{array}{l}\text { Research and nursing } \\
\text { "I am able to integrate research activities } \\
\text { with clinical and nursing procedures" }\end{array}$ & $\begin{array}{l}\text { "I am able to integrate research } \\
\text { with nursing activities" }\end{array}$ \\
\hline
\end{tabular}

\section{Results}

\subsection{Respondents Profile}

Nurses $(n=179)$ from educational settings and clinical practice attended one of these 3 research seminars and 168 of them answered the questionnaires, giving a response rate of 93.85 percent. Of these responses, 121 were from nurses at operational level who provided direct patient care. These data were analysed and reported separately in Nurse Education Today (Loke et al. 2012). The remaining 47 attendees were of interest in this study (Table 2) and their responses were analysed and reported in this paper.

Upon examining the descriptive data, $42(89.4 \%)$ of the respondents were found to be females and $5(10.6 \%)$ were 
male. Many participants were in the age range $40-49(n=18$; $38.3 \%)$ and $50-59(\mathrm{n}=15 ; 31.9 \%)$. All 47 respondents were in possession of either a diploma or a certificate in nursing and many had additional nursing qualifications (First degree: $n=39$; Master's: $n=14$ ). This would suggest previous exposure by the majority of respondents to research, albeit at different stages in their education experience (Table 2).

Twenty six respondents were in some form of managerial position: 13 nurse mangers; 1 assistant director, 1 director, 10 nurse clinicians, 1 advance practice nurse. Twenty-one were in teaching roles; 20 nurse lecturers and 1 nurse clinical educator (Table 2). Of the nurse directors and managers, $14(29.8 \%)$ were employed in large teaching hospitals, $3(6.4 \%)$ in non-teaching hospitals, $10(21.2 \%)$ in private settings. Of the 20 nurse lecturers, 19 (40.4\%) delivered pre-registration and post-registration nursing programmes in higher education institutions and 1 (2.1\%) delivered pre-enrolled nursing programmes in a vocational education setting. Due to the strong evidence-based culture in all healthcare settings and nurse education where quality care was critical, these respondents were presumably working in a research-focused environment (Table 3 ).

Table 2. Demographic Data

\begin{tabular}{|c|c|c|}
\hline & $\begin{array}{c}\text { Respondents } \\
(\mathrm{n}=47)\end{array}$ & $\%$ \\
\hline Gender & & \\
\hline Female & 42 & 89.4 \\
\hline Male & 5 & 10.6 \\
\hline Age & 2 & 4.3 \\
\hline $20-29$ & 12 & 25.5 \\
\hline $30-39$ & 18 & 38.3 \\
\hline $40-49$ & 15 & 31.9 \\
\hline $50-59$ & & 83.0 \\
\hline Education (highest degree) & 39 & 29.8 \\
\hline First degree & 14 & 0 \\
\hline Master's degree & 0 & 42.6 \\
\hline PhD & & 2.1 \\
\hline Roles & 1 & 2.1 \\
\hline Lecturer & 1 & 21.3 \\
\hline Clinical Educator & 10 & 27.7 \\
\hline Advance Practice Nurse & 13 & 2.1 \\
\hline Nurse Clinician & 1 & 2.1 \\
\hline Nurse Manager & 1 & \\
\hline Assistant Nurse Director & & \\
\hline Nurse Director & & \\
\hline
\end{tabular}

Table 3. Participant Employment

\begin{tabular}{|l|c|c|}
\hline Affiliation & $\begin{array}{c}\text { Respondents } \\
(\mathrm{n}=47)\end{array}$ & $\%$ \\
\hline $\begin{array}{l}\text { Further (post-secondary) Education } \\
\text { Institution }\end{array}$ & 1 & 2.1 \\
\hline Higher Education Institution & 19 & 40.5 \\
\hline Large acute teaching hospitals & 14 & 29.8 \\
\hline $\begin{array}{l}\text { Non-teaching hospitals } \\
\text { (restructured/private) }\end{array}$ & 3 & 6.4 \\
\hline Private hospitals & 9 & 19.1 \\
\hline Private nursing homes/Care homes & 1 & 2.1 \\
\hline
\end{tabular}

\subsection{Respondents Research knowledge}

All respondents had been exposed to research based on either their journey in nursing education or in their work environment, and had the required research knowledge (Table 4). Indeed, for methodologies and research designs, while $26(55.3 \%)$ respondents claimed to have knowledge of all three research approaches, only $2(4.3 \%)$ claimed 
absence of knowledge of any research paradigms. Nevertheless, when analysis was made by each research paradigm, more respondents claimed knowledge of the quantitative methods $(\mathrm{n}=43 ; 91.5 \%)$ compared to qualitative approaches $(\mathrm{n}=35 ; 74.5 \%)$.

As for the mixed-methods approach, it was least understood by the respondents $(n=30 ; 63.8 \%)$, albeit it being a very useful nursing research method. In the qualitative findings, whilst one of the nurse managers suggested the need for "...support to increase research knowledge to understand what retrospective study and blinding were", another wished to learn how to conduct an interview. These findings were consistent with the quantitative findings, in the sense that not all respondents had the required knowledge and skills for quantitative as well as qualitative research approaches. Some respondents $(n=9 ; 0.19 \%)$ indicated the reasons for reluctance to undertake research was the lack of confidence resulting from inadequate understanding. The response reflected respondents' awareness of their limitations, as many $(n=35 ; 74.5 \%)$ expressed that they were keen to acquire research knowledge and skills.

Table 4. Research Knowledge

\begin{tabular}{|c|c|c|c|}
\hline \multirow{2}{*}{\multicolumn{2}{|c|}{ "I know..." }} & $\mathrm{n}=47$ & $\%$ \\
\hline & & \multicolumn{2}{|c|}{ YES } \\
\hline \multicolumn{2}{|c|}{ Research Methodologies } & & \\
\hline \multicolumn{2}{|c|}{ Quantitative } & 43 & 91.5 \\
\hline \multicolumn{2}{|c|}{ Qualitative } & 35 & 74.5 \\
\hline \multicolumn{2}{|c|}{ Mixed-methods } & 30 & 63.8 \\
\hline \multicolumn{2}{|c|}{ Quantitative+ Qualitative+ Mixed-methods } & 26 & 55.3 \\
\hline \multicolumn{2}{|c|}{ None } & 2 & 4.3 \\
\hline \multicolumn{4}{|c|}{ Research Sampling Methods } \\
\hline \multicolumn{2}{|c|}{ Probability sampling methods } & 38 & 80.9 \\
\hline \multicolumn{2}{|c|}{ Non-probability sampling } & 34 & 72.3 \\
\hline \multicolumn{4}{|c|}{ Research Methods } \\
\hline \multirow{6}{*}{ Quantitative } & Randomised controlled trial & 34 & 72.3 \\
\hline & Surveys & 42 & 89.4 \\
\hline & Case & 12 & 25.5 \\
\hline & Case, Series & 12 & 25.5 \\
\hline & Cohort, Prospective or Longitudinal & 21 & 44.7 \\
\hline & Case Control or Retrospective & 16 & 34 \\
\hline \multirow{6}{*}{ Qualitative } & Semi Structured Interview & 23 & 48.9 \\
\hline & In-depth Interviews & 17 & 36.2 \\
\hline & Participant Observation & 24 & 51.1 \\
\hline & Non-Participant Observation & 9 & 19.1 \\
\hline & Documentation (text analysis) & 11 & 23.4 \\
\hline & Anecdotal Records and Diaries & 7 & 14.9 \\
\hline \multicolumn{4}{|c|}{ Data Analytic Procedure } \\
\hline \multicolumn{2}{|c|}{ Quantitative methods } & 30 & 63.8 \\
\hline \multicolumn{2}{|c|}{ Qualitative methods } & 19 & 40.4 \\
\hline \multicolumn{2}{|c|}{$\begin{array}{l}\text { Desire for knowledge for conducting Research } \\
\text { "I need more knowledge for conducting research" }\end{array}$} & 35 & 74.5 \\
\hline
\end{tabular}

Whilst acknowledging the general lack of research knowledge and skills, a few respondents from clinical $(n=3$; $6.4 \%$ ) felt that nurse managers in a higher hierarchy should bear the responsibility in addressing the problem of knowledge and skills deficit. Nurse managers highlighted the fact that nursing directors "only go as far as asking us to do research but provided no support". Although holding this view, some $(n=44 ; 93.6 \%) \quad$ sought knowledge independently such as reading research papers on patient care and nursing practice (Table 5). However, not many respondents accessed research papers from the various online sources; academic electronic search engines $(n=18$; $38.3 \%)$ and common search engines $(n=29 ; 61.7 \%)$. A small number of respondents $(n=9 ; 19.1 \%)$ were not aware that a support system from employers and educational organisations was in place for free access to papers. While that was the case, $26(55.3 \%)$ claimed to be unwilling to pay for access. Nevertheless, some $(n=23 ; 48.9 \%)$ asked colleagues to access papers and sought peer support to discuss papers $(n=13 ; 27.7 \%)$. However, based on cross tabulation, there were a considerable number of respondents $(\mathrm{n}=22 ; 46.8 \%)$ who did not approach colleagues for support and also did not access papers electronically.

\subsection{Respondents' experience in conducting research}

Many respondents had research experience but were limited to helping nursing and medical colleagues to conduct research (Table 6). Henceforth, respondents were generally exposed to either survey based research $(n=35$; $74.5 \%)$ or randomized controlled trials $(n=12 ; 25.5 \%)$. This 
explained why more respondents claimed to have knowledge of either survey-based research $(n=42,89.4 \%)$ or randomised controlled trials $(n=34,72.3 .4 \%)$ with very few claiming experience in the qualitative paradigm in semi-structured interviews $(\mathrm{n}=12 ; 25.5 \%)$ and in participant observation $(n=7 ; 14.9 \%)$.

When asked if they had knowledge in data analyses, only $30(63.8 \%)$ had knowledge of quantitative methods, with very few $(n=19 ; 40.4 \%)$ of qualitative methods. This finding was consistent with the claim that nurses usually supported colleagues, especially in non-nursing research, and more critically, strongly suggested that the research experience did not go beyond data collection. Apparently, experience with data analysis was limited, and experience of involvement in research as a co-investigator was rare. This finding was consistent with the qualitative finding which revealed the perception of 4 nurse lecturers who felt that they had neither the adequate knowledge to identify research questions pertaining to nurse education nor the required skills to conduct research. In a similar vein, a few in clinical practice $(n=6)$ highlighted the need for a facilitator to help with acquiring research skills, as one of them explained: “...research is intimidating. To conduct research needs mentorship, unfortunately, many nurses in clinical [sic][areas] are themselves weak in this and will not be good mentors...". Supporting this view was a nurse manager who felt that nurses cannot produce good research, because nurses "are without good research knowledge and skills".

Table 5. Research Preparation

\begin{tabular}{|l|c|c|}
\hline \multirow{2}{*}{ "I engage in activities such as..." } & $\mathrm{n}=47$ & $\%$ \\
\cline { 2 - 3 } & \multicolumn{2}{|c|}{ YES } \\
\hline Read research papers on nursing practice and patient care & 44 & 93.6 \\
\hline Discuss research papers with colleagues & 19 & 40.4 \\
\hline Obtaining Research paper from & & \\
\hline colleagues & 13 & 27.7 \\
\hline local libraries & 34 & 72.3 \\
\hline academic search engines & 18 & 38.3 \\
\hline Google and Yahoo & 29 & 61.7 \\
\hline employer libraries/search engines subscribed by employers & 3 & 6.4 \\
\hline Obtaining free access to research paper & & \\
\hline From Colleagues & 9 & 19.1 \\
\hline From Employer & 25 & 53.2 \\
\hline From Educational Institution where I was/am a student & 14 & 29.8 \\
\hline "I am unaware of free access (by employers and & 9 & 19.1 \\
\hline educational settings)" & & \\
\hline "Not willing to pay for access to research papers" & 26 & 55.3 \\
\hline
\end{tabular}

Table 6. Research Preparation

\begin{tabular}{|c|c|c|c|}
\hline \multirow{2}{*}{\multicolumn{2}{|c|}{ "I have used ..." }} & $\mathrm{n}=47$ & $\%$ \\
\hline & & \multicolumn{2}{|c|}{ YES } \\
\hline \multicolumn{4}{|l|}{ Research Methods } \\
\hline \multirow[t]{6}{*}{ Quantitative } & Randomised controlled trial & 12 & 25.5 \\
\hline & Surveys & 35 & 74.5 \\
\hline & Case & 5 & 10.6 \\
\hline & Case, Series & 1 & 2.1 \\
\hline & Cohort, Prospective or Longitudinal & 5 & 10.6 \\
\hline & Case Control or Retrospective & 3 & 6.4 \\
\hline \multirow[t]{6}{*}{ Qualitative } & Semi Structured Interview & 12 & 25.5 \\
\hline & In-depth Interviews & 4 & 8.5 \\
\hline & Participant Observation & 7 & 14.9 \\
\hline & Non-Participant Observation & 2 & 4.3 \\
\hline & Documentation (text analysis) & 4 & 8.5 \\
\hline & Anecdotal Records and Diaries & 0 & 0 \\
\hline \multicolumn{4}{|l|}{ Nature of involvement } \\
\hline \multirow{3}{*}{$\begin{array}{l}\text { To help colleagues with } \\
\text { data collection }\end{array}$} & Medical doctors & 15 & 31.9 \\
\hline & Nurses & 34 & 72.3 \\
\hline & Other allied healthcare professionals & 4 & 8.5 \\
\hline To help colleagues with & Medical doctors & 1 & 2.1 \\
\hline
\end{tabular}




\begin{tabular}{|c|c|c|c|}
\hline \multirow[t]{2}{*}{ data analysis } & Nurses & 11 & 23.4 \\
\hline & Other allied healthcare professionals & 0 & 0 \\
\hline \multicolumn{2}{|c|}{ As part of their job } & 20 & 42.6 \\
\hline \multicolumn{2}{|c|}{ In the pursuit of a higher degree } & 18 & 38.3 \\
\hline \multicolumn{2}{|c|}{ For career development } & 16 & 34 \\
\hline \multicolumn{2}{|c|}{ To be able to present a paper in conferences } & 9 & 19.1 \\
\hline \multicolumn{2}{|c|}{ Desire for skills for conducting Research } & 35 & 74.5 \\
\hline
\end{tabular}

\subsection{Respondents' perception of the focus and nature of research activities}

While the results demonstrated that respondents had conducted research as part of a team led by medical or nursing professionals, this study also revealed that research was conducted mainly for academic pursuits of a higher degree $(n=18 ; 38.3 \%)$ (Table 6). One nurse lecturer explained "I am not enthusiastic about research, I did it only because of a course, and now it is because I need to teach research to student nurses" In a similar vein, many perceived research as part of their job $(n=20 ; 42.6 \%)$ (Table 7). Nevertheless, there was a general consensus that "research is an invaluable experience in guiding nursing practice".

Many respondents $(n=32 ; 68.1 \%)$ valued research activities in terms of its ability to develop them into being more valuable team members, whilst others $(n=20 ; 42.5 \%)$ claimed that research activity was for improving patient care. Indeed, the qualitative data revealed a summary of these views as explained by a nurse manager, was that "the provision of clear guidelines and transparency between researchers, institutions and patients involved, would ultimately benefit patients". A nurse director also felt that research could "help to foster the culture of interprofessional learning and working". This view was supported by a nurse manager who claimed that "research promotes collaborations between departments and institutions".

Many of the respondents $(n=28 ; 59.6 \%)$ perceived opportunities in conducting research in their area of specialty (Table 7$)$. However, some $(n=19 ; 40.4 \%)$ yearned for protected time for the activity, and insufficient time was raised as a significant barrier for research and assigned as organisational failure. This was expressed by one nurse lecturer who exclaimed disappointedly, "My workplace is an education institution and research is important, yet time off to conduct research is not available" [sic]. Similar concern was raised by a nurse manager within clinical settings, "We are encouraged to conduct research but we are not given time to do it".

Other than not having perceived organisational support in terms of protected time, many respondents felt that research opportunities were confined to the medical professionals. As expressed by one nurse manager, "it was more common for doctors to do research for they had the resources and the privilege to access protected time and funding". Some also felt that conducting research was generally perceived as a superior activity that ironically led to the lack of organisational support for those not deemed to be in the higher hierarchal echelon. As explained by one nurse lecturer, "the bosses could feel threatened if nurse lecturers lead research projects". In addition, nurse lecturers also felt the lack of support from clinical practice, "I can only conduct educational research, it will be very difficult for me to gain access to clinical grounds for research". While that was the case, a nurse manager in the clinical field explained that "not all nurse mangers were research savvy themselves that they can become unsupportive towards colleagues". In this regard, hierarchical power-relations which become barriers to conducting research were experienced by nurse lecturers and nurse managers alike.

Table 7. Respondents' View on Research Opportunities, Values and Organisational Support

\begin{tabular}{|l|c|c|}
\hline \multirow{2}{*}{$\begin{array}{l}\text { 1. Closed Question for 'yes' and 'no' answers } \\
\text { 2. Open question for elaboration }\end{array}$} & $\mathrm{n}=47$ & \multicolumn{2}{|c|}{ YES } \\
\cline { 2 - 3 } Research and Nursing & 28 & 59.6 \\
\hline $\begin{array}{l}\text { "There are research opportunities available in my area of } \\
\text { practice" }\end{array}$ & 22 & 46.8 \\
\hline $\begin{array}{l}\text { "I am able to incorporate research activities with nursing } \\
\text { routines" }\end{array}$ & 32 & 68.1 \\
\hline $\begin{array}{l}\text { Value of research activities } \\
\text { "Conducting research helps me in developing into a } \\
\text { valuable healthcare member }\end{array}$ & 32 \\
\hline
\end{tabular}




\begin{tabular}{|l|c|c|}
\hline $\begin{array}{l}\text { "Conducting research can help with improving patient } \\
\text { care" }\end{array}$ & 20 & 42.5 \\
\hline Issues surrounding research & 19 & 40.4 \\
\hline $\begin{array}{l}|c| \\
\text { "There is protected time to conduct research" }\end{array}$ & 23 & 48.9 \\
\hline $\begin{array}{l}\text { "I have adequate support from managers and medical } \\
\text { doctors to conduct research" }\end{array}$ & 18 & 38.3 \\
\hline $\begin{array}{l}\text { "I am aware that funding are available for research } \\
\text { activities" }\end{array}$ & & \\
\hline
\end{tabular}

\section{Discussion}

Convenience sampling limits generalisabilty, however, the sample in this study includes nurses from various educational and healthcare settings. Hence, the population of nurses was considered adequately represented by those in administrative, education and specialised clinical positions. The sample also reflected the general profile of these nurses in Singapore, in that they either possessed a local nursing diploma qualification or a first degree in nursing. In this regard, they were likely to have been exposed to research in their education. In fact, large numbers of the respondents reported having good research knowledge and skills. However, some still expressed concerns around their lack of research knowledge and skills and reported that they learnt best through mentorship.

Adamsen et al. (2003) once highlighted variances in the nursing curriculum in research training leading to "...the majority of nurses who today work in clinical practice do not have formal or reliable research-related qualifications", (p444). Apparently, this was the case with the Singapore nurses, even if they were in positions which were presumably to facilitate research activities. Albeit being in such unique positions, not all had the confidence to conduct research independently. Fortunately, many of them had engaged in self-directed learning activities, with only some expecting management to address the deficits. In this regard, it might be pertinent to evaluate the research component of the existing nursing curriculum in higher education. Undertaking an evaluation of existing research activity in the curriculum and an assessment of how the research process was taught could lead to changes which would be valuable in transferring the knowledge and skills to useful application in clinical contexts. Without these nurses having the confidence and capability to conduct research, the goal of them shouldering the responsibility and accountability in overseeing nurses engaging with research activities, as outlined by Pettengill et al. (1994), would be difficult to materialise.

Another interesting finding was that the lack of confidence in conducting research was also evidenced. This finding dismissed the idea of research activities being confined to academia as assumed by Jolley (2012). The power relations based on hierarchy in nursing education were as strong as that identified by Hagbaghery et al. (2004) in clinical contexts. Those in higher management positions would not devolve autonomous decision making opportunities to those lower in rank. These nurses were frustrated by the lukewarm managerial support, absence of protected time and unequal funding allocation for research. The overall responses indicated the lack of research opportunities as being attributed to hierarchical remits that beneficiaries were more likely to be channeled to the medical system.

Many of these nurses recognised the potential of research for increasing interprofessional learning and working, and through inclusivity and recognition of all healthcare practitioners, which would lead to improvements in the quality of nursing care and ultimately benefiting the patients. They qualified this by discussing the need to develop an effective interprofessional context between education and practice to increase knowledge and involvement in research activities. Hence, in contrast to previous research studies about nurses (Clifford \& Murray 2001, Kuuppelomaki \& Tuomi 2003), these nurses not only had a strong interest but also an enthusiasm for research.

Overall, despite the formidable barriers, these nurses exhibited willingness and enthusiasm and indeed an ambition to be involved in the research process to benefit patient care. One cannot deny that these characteristic features might not be in every nurse administrator, educator or clinician in Singapore. Claiming generalisability and representation of the findings was not the aim of this study, the important finding as revealed, was that such enthusiasm amongst nurses who ironically were in the unique position to facilitate research and yet did not help in breaking down the barriers of organisational culture or constraint in conducting research. Whilst Rycroft-Malone (2008) highlighted that nurse education had failed to produce research activity, this study revealed oversimplification of barriers to development of analytical research knowledge and skills, and highlighted the overpowering effects of more complex issues of cultural and organisational barriers.

In essence, by employing a mixed-method approach, the emerging themes from the qualitative data were mapped against the quantitative findings. Critical findings emerged around the lack of transferability of nurses' knowledge and skills due to time constraints and the ability to undertake team working in research, alongside limited organisational support. Without generalising findings, this study has provided some valuable and interesting insights into the views of nurses in critical positions to facilitate research, with regards to the barriers affecting their ability to undertake research, and the need for organisational culture 
and infrastructure changes. Based on this study, respondents embraced the important reason for undertaking research as gaining evidence to keep up to date to support practice, but felt a lack of organisational support and collaboration, and hence absence of research opportunities. This concurred with previous work that research was regarded as a difficult process for nurses and was basically a rare opportunity for many(Clifford \& Murray 2001, Kuuppelomaki \& Tuomi 2003). Findings in this study specifically demonstrated that there was willingness and enthusiasm from these nurses to participate in research activities but that organisational culture as imposed by the nursing hierarchical infrastructure inhibited its development. Consequently, research within healthcare and higher education settings remain inhibited with minimal collaborative research between the two.

\section{Conclusions/Implications for practice}

Findings in this study were as disturbing as in other parts of the world. Nursing research culture did not occur as expected despite the evidence-based movement. Evidently, Singapore has even gone an extra mile to develop and groom selected groups of individuals in the hope that they could fully embrace evidence based practice and act as role models to motivate and inspire nursing staff to conduct research. However, the results were similar to that in many other countries; amongst a few of these nurses, research knowledge in terms of research terminologies, methodologies and methods was lacking. In this regard, the focus on nurse educational training needs would have to shift from imparting research knowledge to that of facilitating research skills for utilising in the research process. This is critical because only if research knowledge and skills implanted in the nursing curriculum were experienced by nurses, could it be followed through in nurses' employment. As a result, any understanding of the research process instilled in education can then be continuously experienced in authentic situational work contexts for continual improvement and enhancement throughout their nursing careers at all levels of the nursing

\section{References}

Adamsen, L., Larsen, K., Bjerregaard, L., Madsen, J. (2003). Moving forward in a role as a researcher: the effect of a research method course on nurses' research activity. Journal of Clinical Nursing. 12(3):442-450

Balls, P. (2009). Phenomenology in nursing research: methodology, interviewing and transcribing. Nursing Times. 105(32-33):30-33.

Chiok-Foong Loke, J. (2001). Leadership Behaviours: effects on job satisfaction, productivity and organisational commitment, Journal of Nursing Management. 9(4):191-204.

Clifford, C. (1997). Nurse teachers and research. Nurse Education Today. $17(2): 115-120$

Clifford, C., Murray, S. (2001). Pre- and post-test evaluation of a project to facilitate research development in practice in a hospital setting. Journal of Advanced Nursing. 36(5):685-695.

Clifford, C. (2004). Introduction In: Clifford, C., Clark, J. (eds). Getting Research into Practice. Edinburgh: Churchill-Livingstone, 3-17.

Coghlan, D., Casey, M. (2001). Action Research from the inside: issues and challenges in doing action research in your own hospital. Journal of Advanced Nursing. 35(5):674-682. hierarchy.

Similar to studies in other parts of the world (Clifford \& Murray 2001, Kuuppelomaki \& Tuomi 2003, Oh 2008, Woodward et al 2007), this study also revealed that fundamental research knowledge and skills were not the sole attributes of barriers to nurse leaders as role models. The complexities of the research process were compounded by education and organisational failings as well as by inequalities in power-relations in the work place. An urgent review of the existing organisational culture and infrastructure for equal power relationships is required to address hierarchical obstacles. The review should also aim to improve organisational support in terms of equitable mentoring support, protected time and financial assistance for research. As more money and time are invested into nursing research, access to educational and organisational support needs to be made equitable and transparent. Future research should also explore the possibility for nurses in administrative, educational and specialist clinical positions to conduct research for further development as enhanced role models to motivate and inspire nurses at operational level to the same.

\section{Acknowledgment}

The authors thank all participants for the study. We would also like to thank the following personnel for their permission to conduct the study: Ms Audrey Saw (Deputy Chair of Critical Care Chapter of Singapore Nursing Association -SNA); Ms Jessica Leong (Chair of Operating Room Chapter - SNA); Miss Wong Luan Wah (Director of Nursing in Nanyang Polytechnic- NYP) and Miss Rosline Ang (Operation Manager in NYP). We also like to thank Ms Loi Mei Ling (lecturer of NYP) for her support in one way or another for the success of this study and last but not least, Mr Bryant $\mathrm{K}$ Lee for his help in data analysis and the drafting of this article.

Cooke, J., Owen, J., Wilson, A. (2002). Research and development at the health and social care interface in primary care: a scoping exercise in one National Health Service region. Health and Social Care in the Community. 10(6):435-444.

Fitzgerald, M., Milberger, P., Tomlinson, P.S., Peden-Mcalpine, C., Meiers, S.J., Sherman, S. (2003). Clinical nurse specialist participation on a collaborative research project: barriers and benefits. Clinical Nurse Specilaist.17(1):44-49

Flesner, M. K., Scott-Cawlezell, J., Rantz, M. (2005). Preparation of Nurse Leaders in the $21^{\text {st }}$ Century Workplace. Nurse Leader 3(4), 37-40.

Gill, P. (2004). Difficulties in developing a nursing research culture in the UK. British Journal of Nursing. 13(14), 876-879.

Hagbaghery, M.A., Salsali, M., Ahmadi, F. (2004).The factors facilitating and inhibiting effective clinical decision making in nursing: A qualitative study. BMC Nursing. 3(2):1-11

Hicks, C. (1996). The potential impact of gender stereotypes of nursing research. Journal of Advanced Nursing. 24(5):1006-1013.

Jolley, S. (2002).Raising research awareness: a strategy for nurses. Nursing Standard. 16(33):33-39.

Jones, T. (2010). A Holistic Framework for Nursing Time: Implications for Theory, Practice, and Research. Nursing Forum. 45(3):185-196. 
Joyce, P. (2009) Leadership and organisational effectiveness - lessons to be drawn from education? Journal of Nursing Management.17(4):494-502.

Kouzes, J.M., Posner, B. Z. (2012). The Leadership Challenge: How to Make Extraordinary Things Happen in Organizations. Jossey-Bass: San Francisco.

Kuuppelomaki, M., Tuomi, J. (2003). Finnish nurses' views on their research activities. Journal of Clinical Nursing. 2(4):589-600.

Loke, J. (2001). Evidence Based Practice: Nursing Implications. $5^{\text {th }}$ Asia \& Pacific Nurses Convention. 2001. Singapore. http://www.aspan.bizhosting.com/conventiontheme.htm accessed on 28.03.2013.

Loke, J. C. F., Laurenson, M., Lee, K. W. (2012). Embracing a culture in conducting research requires more than nurses' enthusiasm. Nurse Education Today. http://dx.doi.org/10.1016/j.nedt.2012.09.006

McNicholl, M., Coates, V., Dunne, E. (2008). Driving towards an improved research and development culture. Journal of Nursing Management. 16(3):344-351.

Meyer, J., Johnson, B., Proctor, S., Bryar, R., Rozmovits, L. (2003). Practitioner research: exploring issues in relation to research capacity building. NT Research 8 (6):407-417.

Milner, F. M. (2005). Clinical nurse educators as agents for change: increasing research utilization. International Journal of Nursing Studies. 42(8):899-914.

Nelson, P. J., Holland, D.E., Derscheid, D., Tucker, S. J. (2007). Clinical Nurse Specialist influence in the conduct of research in a clinical agency. Clinical Nurse Specialist. 12 (2):95-100.

Oh, E.G. (2008). Research activities and perceptions of barriers to research utilisation amongst critical care nurses in Korea. Intensive and Critical Care Nurses. 24(5):314-322.

Pettengill, M.M., Gillies, D.A., Clark, C. C. (1994). Factors encouraging and discouraging the use of nursing research findings. Journal of Nursing Scholarship. 26(2):43-147.

Premararni, K. (2006). A longitudinal study of advanced practice nursing in Singapore. Critical Care Nursing Clinics Of North America. 18(4):545-551
Profetto-McGrath, J., Smith, K.B., Hugo, K., Patel, A., Dussault, B. (2009). Nurse educator's critical thinking disposition and research utilisation. Nurse Education in Practice. 9(3):199-208.

Redwood, S. (2005).Colliding discourses: deconstructing the process of seeking ethical approval for a participatory evaluation project. Journal of Research in Nursing. 10(2): 217-230.

Reiter, F. (1996). The Nurse-Clinician. The American Journal of Nursing 66(2):274-280.

Roxburgh, M. (2006). An exploration of the factors which constrain nurses from research participation. Journal of Clinical Nursing. 15(5):535-545.

Ryan, G.W., Bernard, H.R. (2003) Techniques to Identify Themes, Field Methods. 15(1): 85-109.

Rycroft-Malone, J. (2008). Evidence-informed practice: from individual to context. Journal of Nursing Management, 2008. 16(4):404-408.

Tan, M., Zümrüt, A.S., Funda, K.Ö. (2012). Barriers of research utilisation from the perspective of nurses in Eastern Turkey. Nursing Outlook 60(1):44-50.

Tanner, J., Hale, C. (2002). Research-active nurses' perceptions of the barriers to undertaking research in practice. NT Research. 7(5):363-375.

Terry, S., Sitterding, M., Broome, M.E., McCaskey, M. (2011). Engaging and developing research leaders in practice: creating a foundation for a culture of clinical inquiry. Journal of Paediatric Nursing. 26(50):480-488.

Thompson, C., McCaughan, D., Cullum, N., Sheldon, T.A., Mulhall, A., Thompson, D. R. (2001) The accessibility of research-based knowledge for nurses in United Kingdom acute care settings. Journal of Advanced Nursing. 36(1):11-22.

Tsai, S. (2000). Nurses' participation and utilisation of research in the republic of China. International Journal of Nursing Studies. 37(5):435-444.

Woodward, V., Webb, C., Prowse, M. (2007). The perceptions and experiences of nurses undertaking research in the clinical setting. Journal of Research in Nursing. 12(3):227-244 